\title{
DESENVOLVIMENTO DE UM SISTEMA PORTÁTIL PARA REGISTRAR LARVAS DE PEIXES MARINHOS RECÉM COLETADAS E CRIAÇÃO DE BASES DE DADOS SOBRE PEIXES RECIFAIS DO SUL DA BAHIA
}

\author{
AUTOR: BEATRIZ STEPHANE BARBOSA DOS SANTOS \\ CO-AUTOR/ORIENTADOR: FABIANA CEZAR FELIX HACKRADT
}

\begin{abstract}
Resumo: A ictiofauna marinha é um recurso fundamental no fornecimento de alimento e renda para diversas populações costeiras ao redor do mundo, sendo de grande importância o conhecimento ecológico e de distribuição dos estoques pesqueiros. Informações sobre os estágios iniciais da história de vida dos peixes ainda são escassos, e muitas espécies ainda carecem de dados sobre seus estágios de desenvolvimento, a duração desses estágios ou ainda as características morfometrias que definem os mesmos. Como tentativa de amenizar essa problemática, um Guia de Identificação está sendo desenvolvido a partir da análise das fotografias de larvas e pós-larvas de peixes capturadas em regiões recifais e estuarinas da costa da Bahia e do Espírito Santo. Para a construção do Guia foram mensurados e fotografados indivíduos representando 60 espécies de peixes pertencentes a 56 gêneros e 38 famílias. Diante da falta de suporte para a identificação das espécies ainda nos estágios iniciais de vida, o guia ilustrado é uma ferramenta útil para a identificação de espécies de peixes. Adicionalmente, o guia conterá novas informações sobre a distribuição das espécies nas áreas de estudo.
\end{abstract}

Palavras-chave: Ictiofauna, banco de dados, larval, guia. 